\title{
A Control Method of High Impact Energy and Cosimulation in Powder High-Velocity Compaction
}

\author{
Dongdong You $\mathbb{D}^{1},{ }^{1,2,3}$ Dehui Liu, ${ }^{1}$ Hangjian Guan, ${ }^{1}$ Qingyun Huang, ${ }^{1}$ Zhiyu Xiao, ${ }^{1,3}$ \\ and Chao Yang ${ }^{1,3}$ \\ ${ }^{1}$ National Engineering Research Center of Near-Net-Shape Forming for Metallic Materials, South China University of Technology, \\ Guangzhou 510640, China \\ ${ }^{2}$ Metastable Materials Science and Technology State Key Laboratory, Yanshan University, Qinhuangdao 066004, China \\ ${ }^{3}$ Guangdong Key Laboratory for Processing and Forming of Advanced Metallic Materials, South China University of Technology, \\ Guangzhou 510640, China
}

Correspondence should be addressed to Dongdong You; youdd@scut.edu.cn

Received 6 March 2018; Revised 21 June 2018; Accepted 8 July 2018; Published 29 July 2018

Academic Editor: Simo-Pekka Hannula

Copyright (C) 2018 Dongdong You et al. This is an open access article distributed under the Creative Commons Attribution License, which permits unrestricted use, distribution, and reproduction in any medium, provided the original work is properly cited.

\begin{abstract}
To enhance the impact energy of powder high-velocity compaction (HVC) and thus improve the green density and mechanical properties of the resulting compacts, a mechanical energy storage method using combination disc springs is proposed. The high impact energy is achieved by modifying existing equipment, and the hydraulic control system is developed to implement the automatic control of the energy produced from the disc springs. An interdisciplinary cosimulation platform is established using the ADAMS, AMESim, and LabVIEW software packages to perform the interactive control of the simulation process and the realtime feedback of the simulation results. A mechanical-hydraulic cosimulation of the energy control virtual prototype of the testing machine is conducted using this platform. The influence of the impact energy on the green density is studied according to the HVC experimental results of the iron-based powders, and then, the green compact with the higher relative density is produced. The experimental results indicate that the energy enhancement method using the combination disc springs is reasonable and that the hydraulic control scheme is reliable.
\end{abstract}

\section{Introduction}

High-velocity compaction (HVC) is widely used in the powder metallurgy (PM) of titanium-, aluminum-, and ironbased alloys as well as magnets and other materials, for example [1-4]. Compared with conventional compaction (CC), HVC improves the green density of metal powders and enhances the uniformity of the density distribution [5]. The advantages of HVC include high impact energy, low cost, low elasticity aftereffect, and small demolding force [6]. In addition, in the consolidation of $\mathrm{Cu}-\mathrm{Al}_{2} \mathrm{O}_{3}$ alloys, compared with hot pressing (HP) and hot extrusion (HE), HVC compacts exhibit high softening temperatures and good mechanical properties at high temperatures [7]. Moreover, combining other methods, green density can be further enhanced in HVC. Zhang et al. [2] enhanced the green density $\left(0.11-0.25 \mathrm{~g} / \mathrm{cm}^{3}\right)$ using the annealed powder in iron-based alloy HVC. Zhang et al. [8] utilized warm die HVC to enhance the green density of an iron-based alloy $\left(0.09-0.27 \mathrm{~g} / \mathrm{cm}^{3}\right)$. Park et al. [9] found that the density of the compact increased under multiple pressures in the magnetic pulsed compaction of Al-Si powders. Jiang et al. [10] studied the high-temperature HVC (HTHVC) of W85-Cu heat sinks and concluded that the HTHVC process significantly increases the density of the tungsten skeleton compact.

During the HVC process, the strong impact stress waves or shock waves generated by the dynamic pressure on the hammer are transmitted into the powder. As a result, the powder rapidly forms and densifies within a period of $0.02 \mathrm{~s}$. Following the application of a high-frequency impact stress wave with an interval of $0.3 \mathrm{~s}$, the powder's relative density can be further improved. As a result, the mechanical 
properties of the metal powder product can be enhanced $[2,5,8]$. Shoaib and Kari [11] simulated nonlinear elastoplastic shock waves in particle systems subjected to HVC using the discrete element method. Li et al. [12] analyzed the shock waves and green density and explored the HVC mechanism of the metal powder based on a mesoscopic approach using the multispeed lattice Boltzmann method. Wang et al. [13] simulated pressure propagation in the HVC process based on the discrete element method; the results revealed a delay phenomenon and serrated waves with different gradients in the loading and unloading processes.

The impact velocity and energy have a critical influence on compact densification during HVC. The impact velocity during HVC is two to three orders of magnitude higher than that of the conventional compaction process [14]. The impact energy during HVC depends on the impact velocity and the weight of the hammer. Yuan et al. [15] analyzed in detail the influence of the impact energy on the maximum impact force, green density, ejection force, spring back, hardness, and bending strength of the compacts in aluminum alloy powder HVC. On this basis, Ti-6Al-4 V powder [16] and Ti$10 \mathrm{Mo}$ alloy powder [17] were used to conduct similar studies. Wang et al. [18] investigated the relationships among the impact velocity, the green density, the sintered density, the bending strength, and the tensile strength of HVC-processed iron powder and noted that, with increasing impact velocity, the green density and the bending strength significantly increased. Moreover, Li et al. [19] obtained similar results in the $\mathrm{HVC}$ of $0.9 \mathrm{Al}_{2} \mathrm{O}_{3} / \mathrm{Cu}$ composite powders. Deng et al. [20] analyzed the influence of the impact energy and velocity on the density and magnetic properties of $\mathrm{NdFeB}$ powders and HVC magnets. In addition, Deng et al. [21] prepared the magnets under various conditions, including impact energy, filling weight, mold dimension, and plasticity. The results of both studies revealed that the density of the as-compacted $\mathrm{NdFeB}$ magnets increased with increasing impact energy. Yan et al. [14] prepared the ring and the cylindrical samples by $\mathrm{Ti}$ powder HVC and found that the green density increased with increasing impact energy, in contrast to decreasing with increasing filling weight. Yan et al. [22] further studied the influence of particle size on the green density. The authors believed that the green density of compacts is mainly determined by the particle size of the powders at relatively larger impact energies. Subsequently, the pure Ti powder was replaced by Ti-6Al-4 V [23] and Ti-4.5Al-6.8Mo-1.5Fe [24] powder, and similar results were obtained. Eriksson et al. [25] investigated the influence of different impact energies on HVC behavior in the formation of a dental coping made from titanium powder.

Many energy storage methods, such as gravity energy storage, hydraulic energy storage, and chemical energy storage, can produce the high speed required for pressing. Sethi et al. [5] listed four types of dynamic compaction equipment of various configurations, namely, guns, rams, electrical impulse, and explosive units, used to produce high impact energy and the corresponding operating parameters. Vivek et al. [3] used a variation of electrically driven vaporizing foil actuators for the dynamic compaction of
Ti-based alloy powders. Babaei et al. [4] utilized the gas mixture detonation method to study experimentally the HVC of aluminum powders. Gustafsson et al. [26] employed a projectile accelerated inside an air gun to generate elasticwave propagation and achieved impact loading. Shoaib et al. [27] incorporated a relaxation assist device into a piston die assembly to better lock the particles during the compaction process and convert the higher kinetic energy of the hammer into particle deformation. Khan et al. [28] studied the influence of the upper relaxation assist device on green density, spring back, green strength, and hardness in the powder HVC of pure iron.

Recently, with the progress of HVC technology, many industrial HVC machines have been developed. Hydropulsor, SKF, and other companies now manufacture a series of industrial hydraulic presses [29, 30]. Doremus et al. [6] developed an industrial hydraulic press with an impact energy of $18 \mathrm{~kJ}$ and impact velocity of $10 \mathrm{~m} / \mathrm{s}$. However, the application of these industrial setups is limited by the high impact velocity that must be promoted, their high cost, and their lack of a built-in heating device [30]. Guan et al. [31] developed a mechanical energy storing HVC laboratory machine with the maximum impact energy as great as $2035 \mathrm{~J}$. The impact energy is produced by the impulse of the hydraulically driven spring on the hammer. The press is employed to consolidate $\mathrm{NdFeB}$ powders into nanocrystalline bulk magnets $[1,20,21]$. However, its impact energy requires further improvement, and this method is difficult to implement in industrial automated production lines. Moreover, the energy storage element, cylindrical spiral spring, suffers from several defects, including small energy storage, poor stiffness stability, and elastic relaxation following long-term usage. Furthermore, energy control is a significant aspect of HVC technology. Sethi et al. [5] believed that once the critical limit of the speed of sound is reached, energy, not velocity, is the critical parameter that controls the shock wave phenomenon for easily compressible materials. At higher energy levels, the velocity has even minor negative effect on the densification.

Currently, mechanical-hydraulic control cosimulation is widely used in mechanical design. A mechanical system can be evaluated and optimized using a multidisciplinary cosimulation platform that considers the structural kinematics and dynamics, hydraulic system, structural strength, control system, and other aspects [32-39]. Zhao et al. [32] proposed a consensus predictive control protocol and a simplified hydraulic mechanism of a $360 \mathrm{MN}$ extrusion machine and illustrated their validity with an ADAMS-EASY5 cosimulation platform. Ye et al. [33] developed a cosimulation platform by using AMESim and MATLAB/Simulink to evaluate the performance of the proposed PID tuning method of a valve-controlled cylinder system employed in a hydraulic excavator. Zhang et al. [34] built a cosimulation model using MATLAB/Simulink and ADAMS to verify the proposed control strategy for a double shaking table system. Zeng et al. [35] used LS-DYNA, ADAMS, and AMESim software packages to construct the drum cutting coal model, the gear transmission model, and the hydraulic system model of the cutting unit of a mining shearer, respectively. 
Data transmission and cosimulation of these three models were implemented with MATLAB.

In this study, impact energy is enhanced by modifying the energy storage method of the existing HVC machine [31] using combination disc springs. Subsequently, a green compact with a $98 \%$ relative density is produced using pure iron powders to verify the method of the energy storage and enhancement. Moreover, the automatic control method of the impact energy is presented and validated via HVC experiments and cosimulation. The presented method and equipment provide a foundation for HVC industrial application to large powder metallurgy parts.

\section{Implementation of High Impact Energy}

The design objective is as follows: pack $14 \mathrm{~g}$ of iron powder into a die with a diameter of $20 \mathrm{~mm}$ and develop the necessary test equipment to produce green compacts with relative densities as great as $98 \%$. According to (1) [40], the maximum impact energy is $2323 \mathrm{~J}$. Assuming that $80 \%$ of the energy stored in the spring can be converted into impact energy, the spring energy storage is at least $2903 \mathrm{~J}$. Consequently, $3000 \mathrm{~J}$ of stored energy is chosen as the design parameter.

$$
\ln \varphi=65.5 \exp \left[0.119\left(\frac{1-P}{\Delta H_{\mathrm{L}}}\right)\right]-72.3,
$$

where $\varphi$ is the green porosity; $P$ is the energy density; and $\Delta H_{\mathrm{L}}$ is the latent heat of powder melting.

2.1. Mathematical Model of Energy and Velocity. The mechanical energy storing HVC press compresses the springs through hydraulic pressure and then releases the energy via spring deformation restoration, pushing the hammer with a high-speed movement. The kinetic energy of the hammer is mainly determined by the energy stored via spring deformation. In the initial condition, the mathematical model of the impact energy can be expressed as

$$
E=E_{\mathrm{p}}+E_{\mathrm{k}}=\frac{1}{2} k x^{2}
$$

where $E$ is the total impact energy; $E_{\mathrm{p}}$ is the potential energy of the mechanism; $E_{\mathrm{k}}$ is the kinetic energy of the mechanism, with $E_{\mathrm{k}}=0$ in the initial condition; $k$ is the average stiffness of the springs; and $x$ is the initial deformation of the springs.

When the compression in the springs is released, the mathematical model of the total kinetic energy of the spring system at any time in the ideal state of motion, that is, without friction or damping, can be expressed as

$$
E=E_{\mathrm{K} 1}+E_{\mathrm{K} 2}=\frac{1}{2} M v^{2}+\frac{1}{2}\left(\frac{m}{3}\right) v^{2}
$$

where $E_{\mathrm{K} 1}$ is the kinetic energy of the hammer; $E_{\mathrm{K} 2}$ is the kinetic energy of the springs; $M$ is the quality of the hammer; $m$ is the quality of the springs; and $v$ is the velocity of the hammer.

Because the length of the impact stroke is small, the value of the gravitational potential energy of the hammer is negligible compared to that of the kinetic energy. Therefore, when the springs are completely released, their deformation energy is transformed almost entirely into the kinetic energy of the impact mechanism. According to (2) and (3), the relationship between the impact velocity and spring deformation can be expressed by the following equation:

$$
v=\sqrt{\frac{k}{M+(m / 3)}}
$$

2.2. Experimental Equipment. High impact energy is implemented by modifying the energy storage method of the existing test machine. The cylindrical spiral spring used in the existing equipment is replaced by the disc spring, which has many advantages, including greater energy storage, small deformation, greater bearing capacity, high space utilization rate, high fatigue life, and low creep tendency. Moreover, because of these advantages, this test system is better suited for mass production in industrial applications.

Figure 1 shows the overall structure of the modified machine, which consists of an energy storage system, an energy control system, and a hydraulic control system.

Figure 2 represents the components associated with energy control. Spring compression is controlled by the designed hollow hydraulic cylinder, in which the sensors are installed at the entrance and exit positions to measure the oil pressure. When the hydraulic cylinder is in operation, the signal of the spring deformation measured by the displacement sensor is accumulated together with the signals from the oil pressure sensor on the programmable logic controller (PLC) to obtain the real-time spring energy storage. Compared with the set value of the energy storage, the value of the real-time energy storage is updated to meet the set value by adjusting the spring deformation and the oil pressure.

2.3. Design of the Disc Spring. To reduce the modifications to the existing machine, the inner diameter of the disc spring is selected as $d>100 \mathrm{~mm}$ and the outer diameter is selected as $D<250 \mathrm{~mm}$ to match the diameter of the original impact $\operatorname{rod}(100 \mathrm{~mm})$. The disc spring is made of $60 \mathrm{Si} 2 \mathrm{MnA}$ spring steel.

The mathematical model of the axial force of the disc spring can be derived as follows:

$$
P=\frac{4 E}{1-\mu^{2}} \cdot \frac{t^{4}}{K_{1} D^{2}} \cdot \frac{f}{t}\left[\left(\frac{h_{0}}{t}-\frac{f}{t}\right)\left(\frac{h_{0}}{t}-\frac{f}{2 t}\right)+1\right],
$$

where $E$ is the elastic modulus of the disc spring; $\mu$ is the Poisson ratio; $t$ is the monolithic spring thickness; $D$ is the spring outer diameter; $f$ is the deformation; $h_{0}$ is the deformation when the spring is planished; and $K_{1}$ is the calculation coefficient, which is expressed as follows:

$$
K_{1}=\frac{1}{\pi} \cdot \frac{[(c-1) / c]^{2}}{(c+1) /(c-1)-2 / \ln c},
$$

where $c=D / d$ and $d=102 \mathrm{~mm}$ is set according to the disk spring design manual [41]. The structure of the monolithic disc spring is shown in Figure 3. 

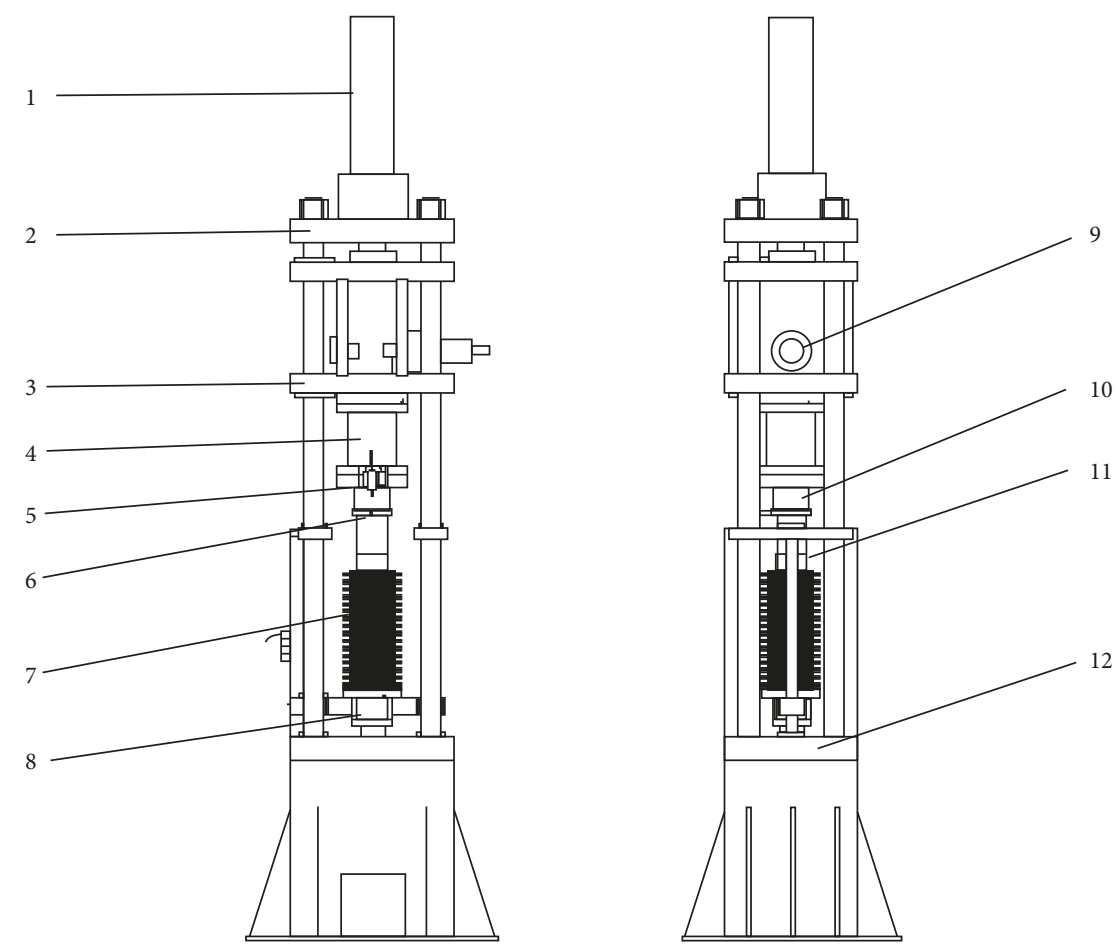

Figure 1: Structure of the modified HVC machine: 1, main hydraulic cylinder; 2, beam; 3, movable beam; 4, hydraulic cylinder; 5 , displacement sensor; 6, spring flange; 7, disc spring; 8, impact hammer; 9, locking hydraulic cylinder; 10, piston rod; 11, guide bar; 12, lower beam.

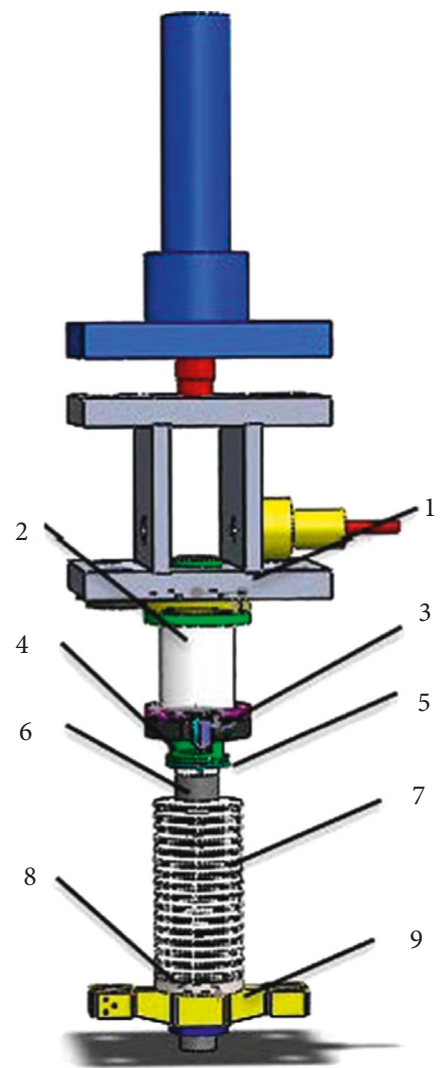

FIGURE 2: Energy control components: 1, movable beam; 2, hydraulic cylinder; 3, displacement wire sensor; 4, piston rod; 5, spring mat flange; 6 , impact rod; 7 , disc spring group; 8 , flange; 9 , hammer head.

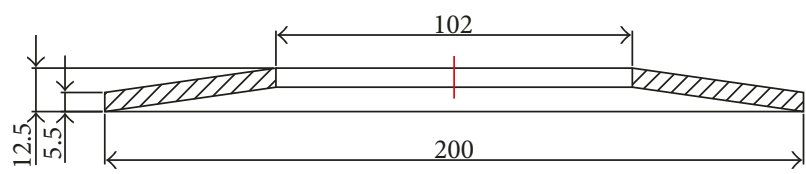

FIgURE 3: Monolithic disc spring size.

The involution combination structure is adopted to ensure that the spring can withstand greater load in the same compression [42]. The parameters are as follows: $E=2.06 \times 10^{5} \mathrm{~N} / \mathrm{mm}^{2}, \mu=0.3$, and $c=D / d=2 . K_{1}$ is calculated using (6). According to the disc spring design manual [41], we take $F_{1}=D / d=2$; by checking the characteristic curve of the disc spring, the deformation $f=4.4198 \mathrm{~mm}$ is obtained.

The energy storage of the monolithic disc spring is as follows:

$$
U=\frac{2 E}{1-\mu^{2}} \cdot \frac{t^{5}}{K_{1} D^{2}} \cdot\left(\frac{f}{t}\right)^{2} K_{4}^{2}\left[K_{4}^{2}\left(\frac{h_{0}}{t}-\frac{f}{2 t}\right)+1\right] .
$$

To meet the requirements of the impact energy of $3000 \mathrm{~J}$, the number of disc springs is $i=32$. Thus, the total energy is $U_{z}=i \times U=3000 \mathrm{~J}$, the total deformation is $f_{z}=i \times f$ $=141 \mathrm{~mm}$, and the spring height is $259 \mathrm{~mm}$ after loading. In brief, the spring can reach $3000 \mathrm{~J}$ when the deformation is approximately $141 \mathrm{~mm}$.

In summary, the design parameters of the disc spring are as follows: the disc spring is made of 60Si2MnA steel, the outer diameter is $D=200 \mathrm{~mm}$, the inner diameter is $d=102 \mathrm{~mm}$, the free height of the monolithic spring is $12.5 \mathrm{~mm}$, the total 
number of pieces of the spring is 32 , and the free height of the combination is $400 \mathrm{~mm}$.

\section{Hydraulic Control System for Spring Energy Storage}

A method for the hydraulic control of the spring system's compression is developed to indirectly control the spring's energy storage. The hydraulic control system mainly consists of three hydraulic cylinders, three reversing valves, an overflow valve, a three-phase asynchronous motor, and a single couplet vane pump. Eight buttons are used to control the movement of the three hydraulic cylinders and the start and stop of the main engine. The maximum oil pressure and the maximum thrust of the hydraulic system are up to $20 \mathrm{MPa}$ and $62439 \mathrm{~N}$, respectively, which meet the requirements of the maximum compression stroke of the springs.

The hydraulic control system frame shown in Figure 4 describes a closed-loop control system. The pump provides power to the valves and the cylinders. After setting the parameters in the PLC, the signals coming from the pressure sensor and the displacement sensor are amplified by the PLC and transmitted to the reversing valve. The oil flow in the cylinder is adjusted via changing the opening size of the reversing valve core. In this manner, the spring displacement can be controlled.

The spring compression is measured by the displacement sensor installed on the hydraulic cylinder, as shown in Figure 5(a). A roller installed on the head of the encoder is connected with the welding bolt and is attached to the flange of the hollow piston rod by a fine wire rope. The roller rotates one circle for 10,000 pulses of the encoder. When compressing the springs, the encoder pulse signal corresponding to the moving distance of the wire rope is converted and amplified to the PLC. The real-time load signal is read by the pressure sensor installed on the oil inlet of the hollow hydraulic cylinder and then is transmitted to the PLC, as shown in Figure 5(b). The control program is completed using the ladder diagram in GX Developer of the MELSOFT software to drive the three reversing valves. The MITSUBISHI FX1N-40MR controller and the MITSUBISHI GT1 150 touch screen are selected as the PLC and the operation panel, respectively. The communication between the two components is implemented through programming in the GT Designer3 and the transparent transfer function of the bus connection GOT.

\section{Cosimulation of Energy Control for the HVC Machine}

The control system model, hydraulic system model, and mechanical model are built in LabVIEW, AMESim, and ADAMS software packages, respectively. The hydraulic interaction control system is established using the LabVIEWoriented interface pattern in LabVIEW and AMESim cosimulation. Through the ADAMS software interface, the mechanical-hydraulic system is combined in AMESim to allow the LabVIEW simulation platform to interactively control the ADAMS mechanical system.

4.1. LabVIEW Simulation Control Panel. In LabVIEW, three functional areas, namely, the input signal control area, the output signal monitoring area, and the debug monitoring area, are designed in the control panel. The operating interface is shown in Figure 6. A virtual button is used to enter the preset spring energy, and a virtual oscilloscope is used to show each of the following curves: spring compression, spring elasticity, and spring energy.

4.2. Cosimulation Modeling. In mechanical system modeling, the three-dimensional model of the combined disc spring established by SolidWorks software is imported into the finite element software to perform the dynamic modal analysis used to build the flexible body of the spring. Subsequently, the MNF file is imported into the ADAMS software to replace the rigid body of the spring group. Next, a rigid-flexible coupling simulation system is built. The assembly constraints of virtual equipment, the spring compression, and the state variables of the spring constraint force are applied based on the forming process.

Regarding the hydraulic system modeling, the components of the hollow double piston rod hydraulic cylinder are modeled by the component library HCD of the AMESim software.

The cosimulation model of mechanical-hydraulic control is shown in Figure 7. The LabVIEW module port is connected to the AMESim model input signal port. In the cosimulation model, the displacement and force proportional elements are used to modify the differences between the unit systems in AMESim and ADAMS. The spring energy storage proportional element is used to modify the relationship of the integral accumulation equation between the spring compression and the spring force.

LabVIEW controls the AMESim hydraulic system to adjust the spring compression and the spring constraint reaction in the ADAMS mechanical system to achieve the given energy value that is imputed in the LabVIEW control panel. The spring compression, the spring constraint reaction, and the spring energy storage are presented on the virtual oscilloscopes.

The cosimulation interactive control program is composed of three main modules: the initialization module, main module, and termination module.

4.3. Results of Cosimulation. The HVC process simulation with a given impact energy of $3000 \mathrm{~J}$ was conducted in the proposed cosimulation platform, as shown in the screen shot of the cosimulation running in Figure 6. In cosimulation, the variables for the spring compression, the spring constraint reaction, and the spring energy in ADAMS and AMESim can be shown on the control panel. With the agreement of the three software results, the software interface, the spring energy automatic control, and the data 


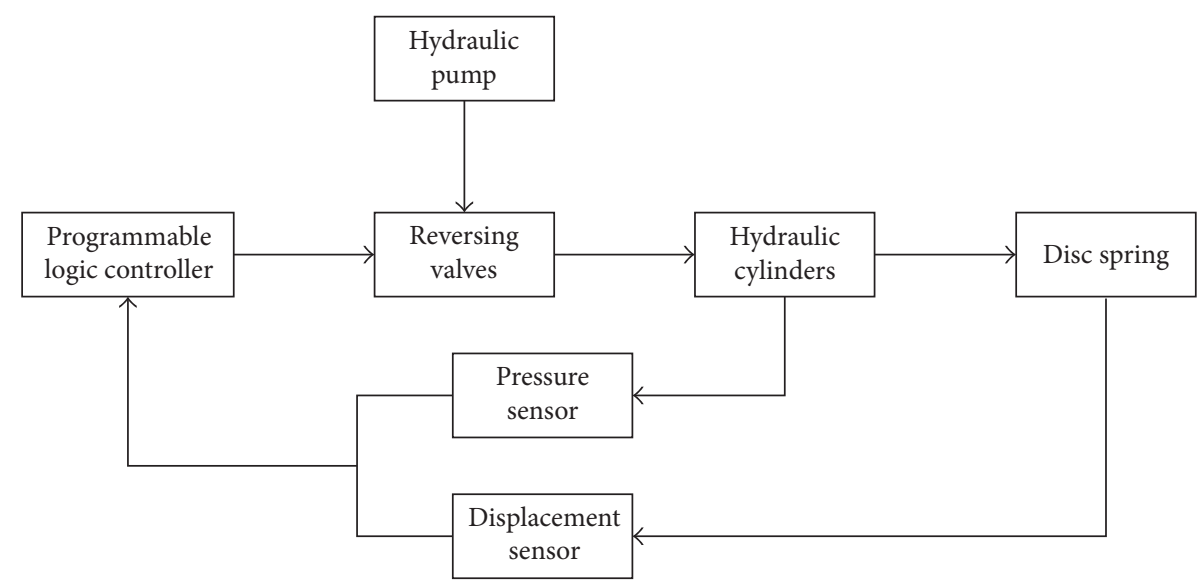

FIgURE 4: Hydraulic control system frame.

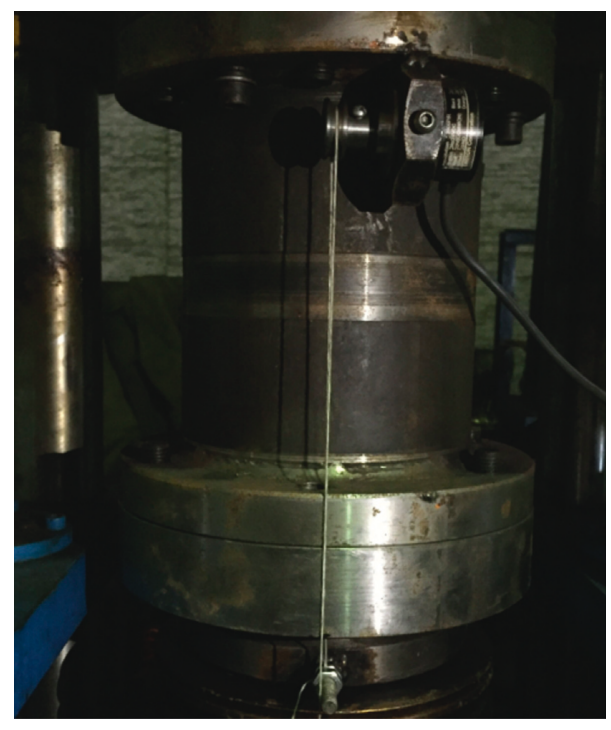

(a)

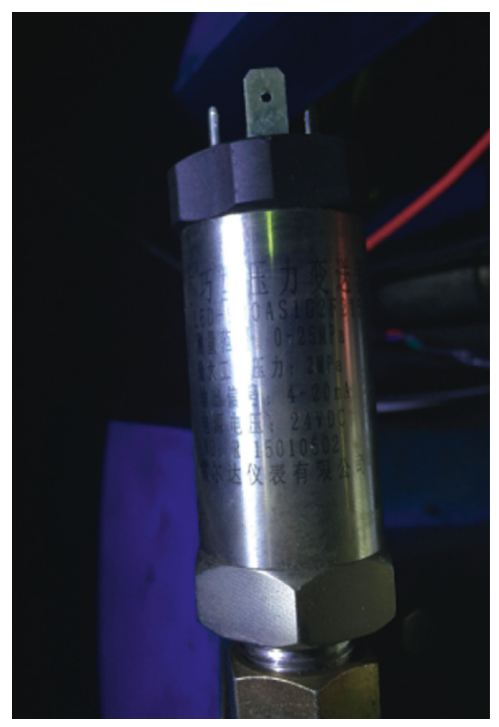

(b)

Figure 5: (a) Displacement sensor and (b) pressure sensor.

real-time interaction of the cosimulation platform are validated.

The spring energy, compression, and reaction data extracted from AMESim are shown in Figure 8, Figure 9, and Figure 10, respectively. Figure 8 shows that the spring energy reaches the setting value of $3000 \mathrm{~J}$ within $2 \mathrm{~s}$. In Figure 9, the maximum spring compression is $109.5 \mathrm{~mm}$. The spring maximum reaction value is $5.484 \times 10^{4} \mathrm{~N}$ as shown in Figure 10. In summary, the simulation results basically coincide with the theoretical results.

\section{Experimental Research}

5.1. HVC Experiment. The developed industrial prototype machine is shown in Figure 11. The disc springs are manufactured according to the design parameters presented in section 2.3, and the stiffness test is conducted on the
$20,000 \mathrm{~N}$ spring tensile test machine. Water-atomized iron powders, with a theoretical density of $7.86 \mathrm{~g} / \mathrm{cm}^{3}$, are used in the experiment. The die ( $\phi 20 \mathrm{~mm}$ inner diameter $)$ is filled with $14 \mathrm{~g}$ of powder. Lithium stearate anhydrous ethanol suspension (1\%) is used as the lubrication, which is uniformly applied on the inner wall of the die and the surface of the upper and lower punches.

Two groups of experiments are conducted: one is the spring energy test, in which the energy values are set to $200 \mathrm{~J}$, $500 \mathrm{~J}, 800 \mathrm{~J}, 1100 \mathrm{~J}, 1400 \mathrm{~J}, 1700 \mathrm{~J}, 2000 \mathrm{~J}, 2300 \mathrm{~J}, 2600 \mathrm{~J}, 2900 \mathrm{~J}$, and $3200 \mathrm{~J}$, and the other is the spring displacement test, in which the displacement values are $40 \mathrm{~mm}, 50 \mathrm{~mm}, 60 \mathrm{~mm}$, $70 \mathrm{~mm}, 80 \mathrm{~mm}, 90 \mathrm{~mm}, 100 \mathrm{~mm}, 110 \mathrm{~mm}, 120 \mathrm{~mm}, 130 \mathrm{~mm}$, and $140 \mathrm{~mm}$. Two green compacts are produced for each different energy value or displacement value. The impact velocity is measured using a photoelectric sensor. The green density is measured and calculated by the wax sealing method. 


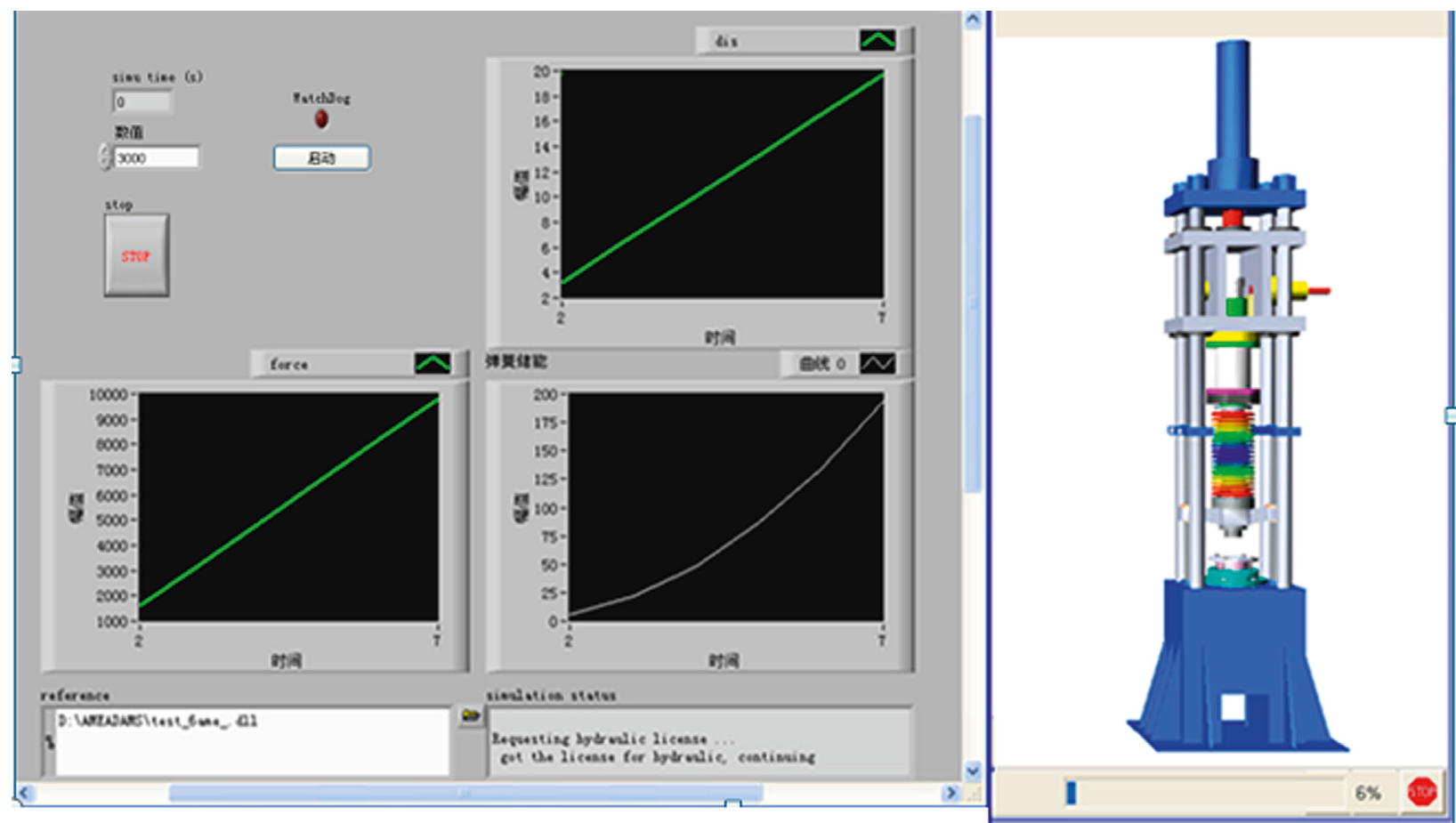

FIgURE 6: Control panel for cosimulation of energy control.

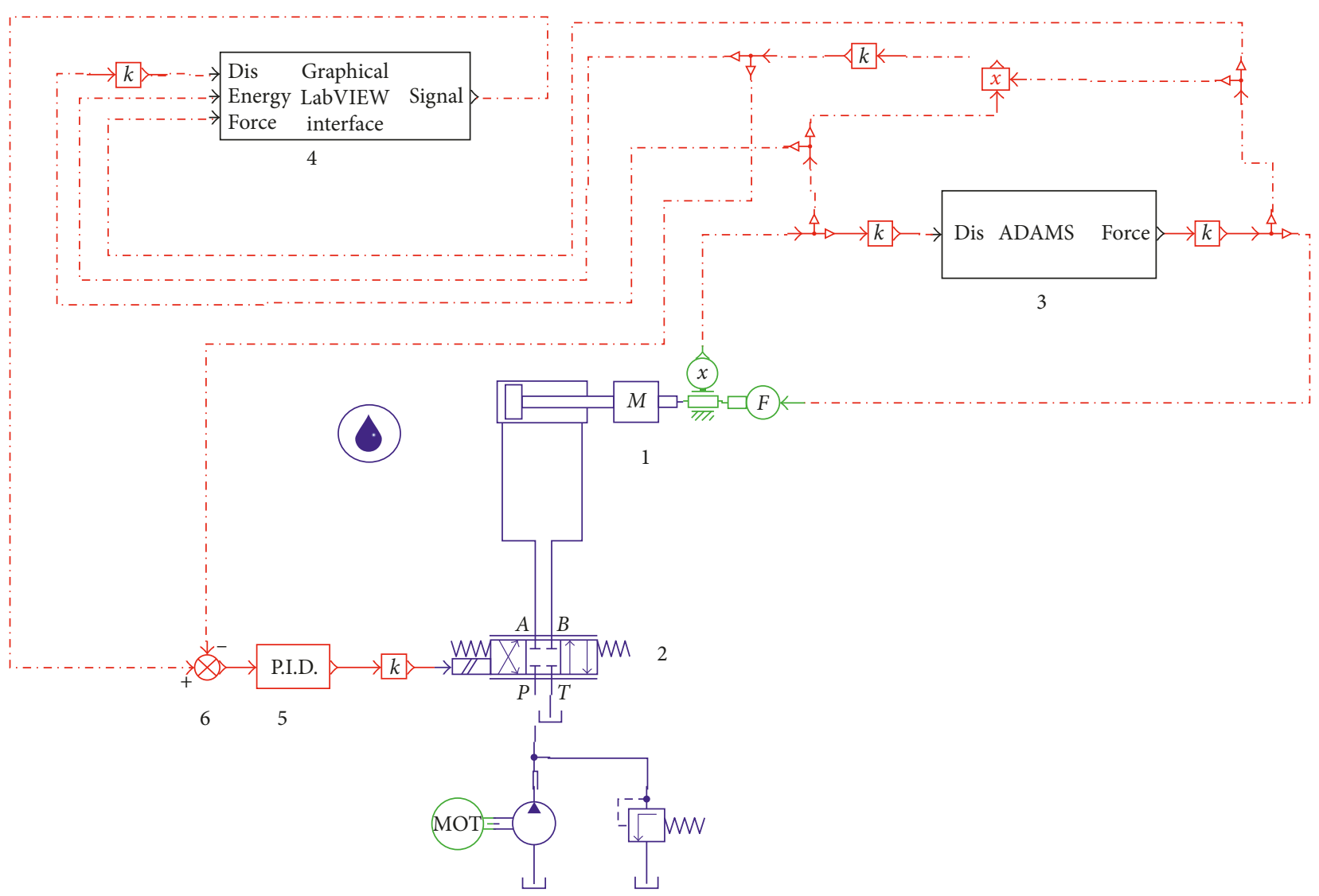

FIGURE 7: Mechanical-hydraulic control cosimulation system: 1, hydraulic cylinder; 2, solenoid valve; 3, interface of ADAMS-AMESim; 4, interface of LabVIEW-AMESim; 5, PID module; 6, signal input port. 


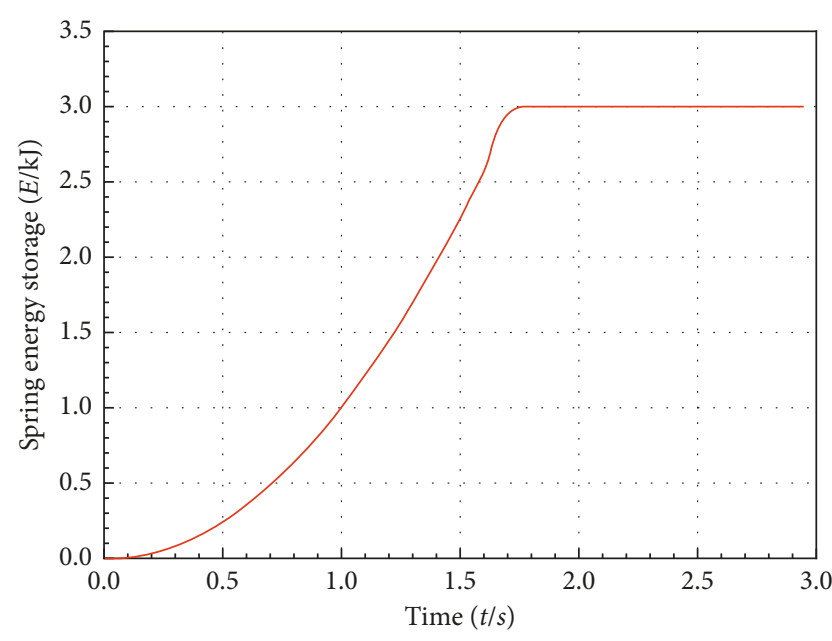

FIGURE 8: Cosimulation result of spring energy from AMESim.

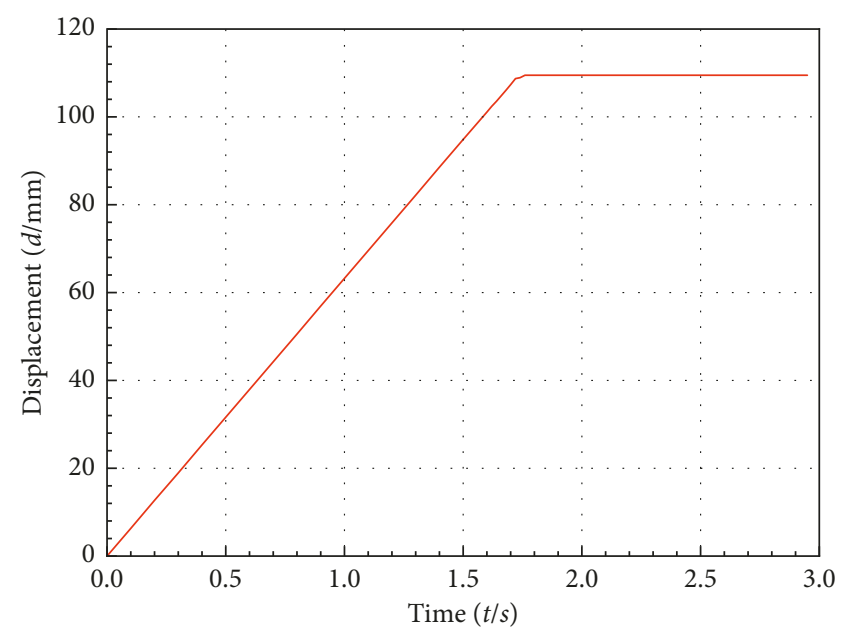

FIGURE 9: Cosimulation result of spring compression from AMESim.

\subsection{Results and Discussion}

5.2.1. Verification of the Mathematical Model of the Impact Energy. Substituting the parameters of the energy storage mechanism of the modified machine into (4), the theoretical calculation curve of the impact velocity can be drawn. The comparative results between the theoretical calculation and the measurement velocity are shown in Figure 12. The two are basically consistent. The results indicate that it is reliable to verify the energy storage of the disc springs according to the mathematical model presented in section 2.1.

5.2.2. Verification of the Impact Energy Control of the Modified Machine. The experimental results for energy storage are shown in Figure 13. The experimental results are found to be in good agreement with the set values in the low energy condition, with a minimum error of $0.7 \%$. However, in the higher energy condition, the maximum error is $7.2 \%$ because of hydraulic fluctuation in the system

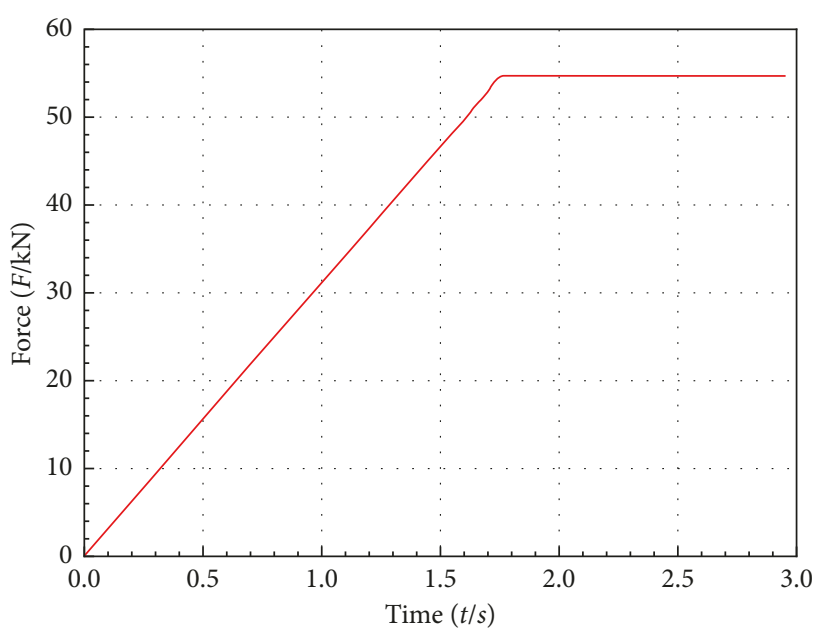

FIGURE 10: Cosimulation result of spring reaction from AMESim.

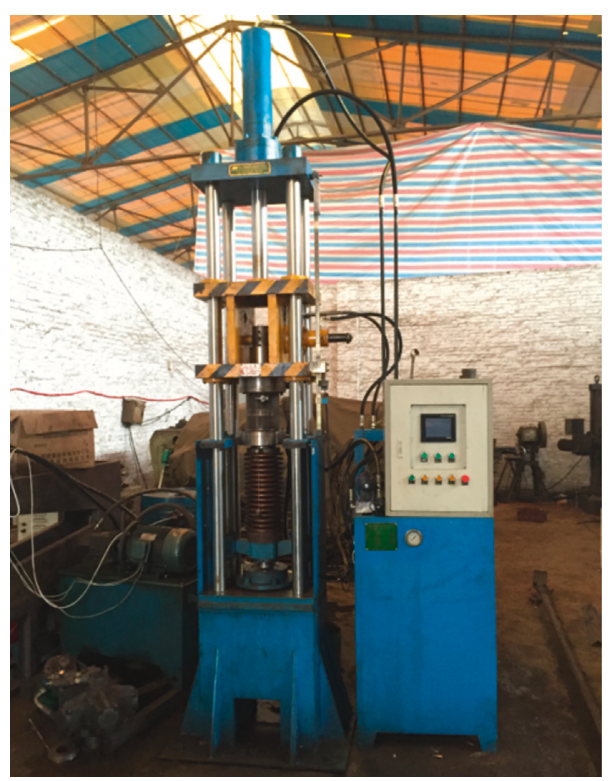

FIGURE 11: Developed industrial prototype machine.

control, shooting time delay, the complexity of the testing environment, the maximum sampling frequency limit of the data acquisition card, and other factors. The experimental results demonstrate that the disc spring combination can improve the energy storage. Moreover, the agreement among the set values, the screen display results, and the experimental results indicates the rationality of the hydraulic automatic control scheme.

\subsubsection{Energy Comparison between the Modified and Existing} Machines. Compared with the cylindrical spiral spring of the existing machine, the disc spring energy storage method presented in this study reduced the height of the machine by $33 \%$ and effectively enhanced the spring energy storage value. Figure 14 shows the relationship between the energy storage value and the deformation of the modified and existing machine with different springs. The energy storage 


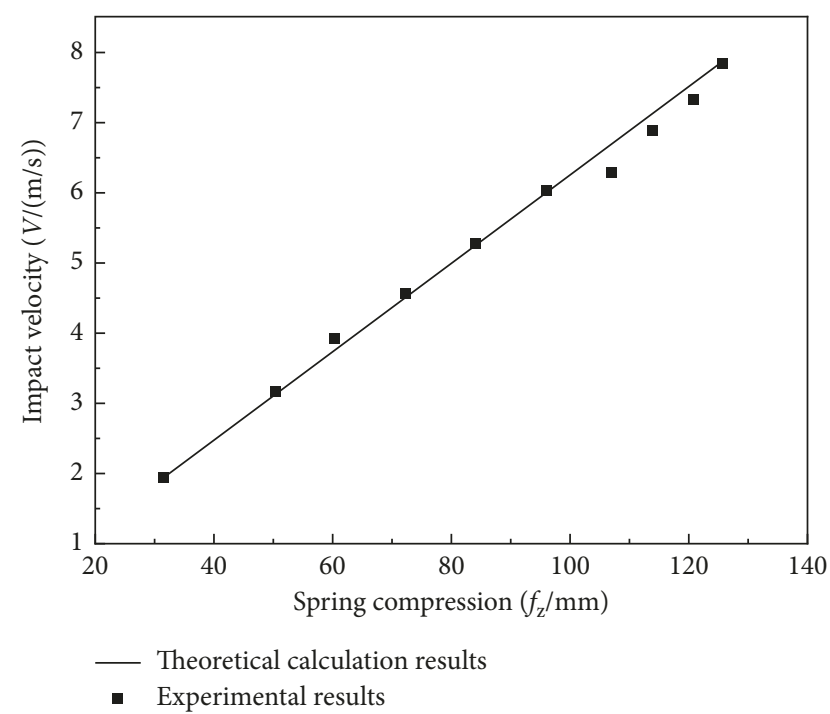

FIGURE 12: Comparison between the theoretical calculation of the velocity and the measured velocity as a function of spring compression.

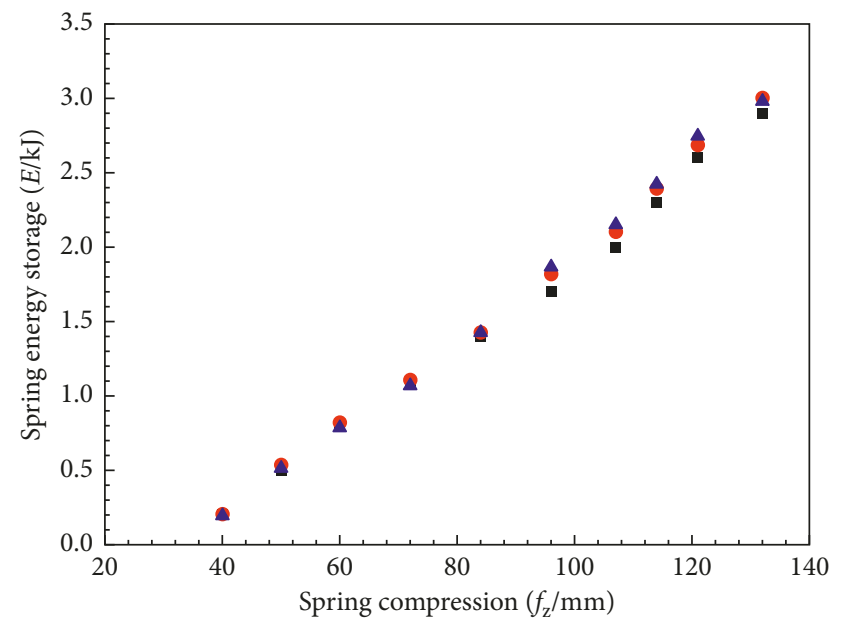

- Set values

- Display results

\ Experimental results

Figure 13: Comparison among the set, display, and experiment results.

capacity of the springs is observed to be enhanced with increasing spring compression. Moreover, at the same compression, the energy storage capacity of the disc spring group is higher. The calculated energy of the disc spring is approximately $3000 \mathrm{~J}$ when the compression is $141 \mathrm{~mm}$.

5.2.4. Compact Density of the Powder Forming Experiment. Figure 15 shows the green compact density of the powder forming experiment. The results indicate that the modified machine has great ability to form powder compactions. The green density is enhanced with the increase of spring compression. When the spring compression increases from $40 \mathrm{~mm}$ to $50 \mathrm{~mm}$, the green density increases from $5.79 \mathrm{~g} / \mathrm{cm}^{3}$ to $6.17 \mathrm{~g} / \mathrm{cm}^{3}$ slowly; when it increases from $50 \mathrm{~mm}$ to $60 \mathrm{~mm}$,

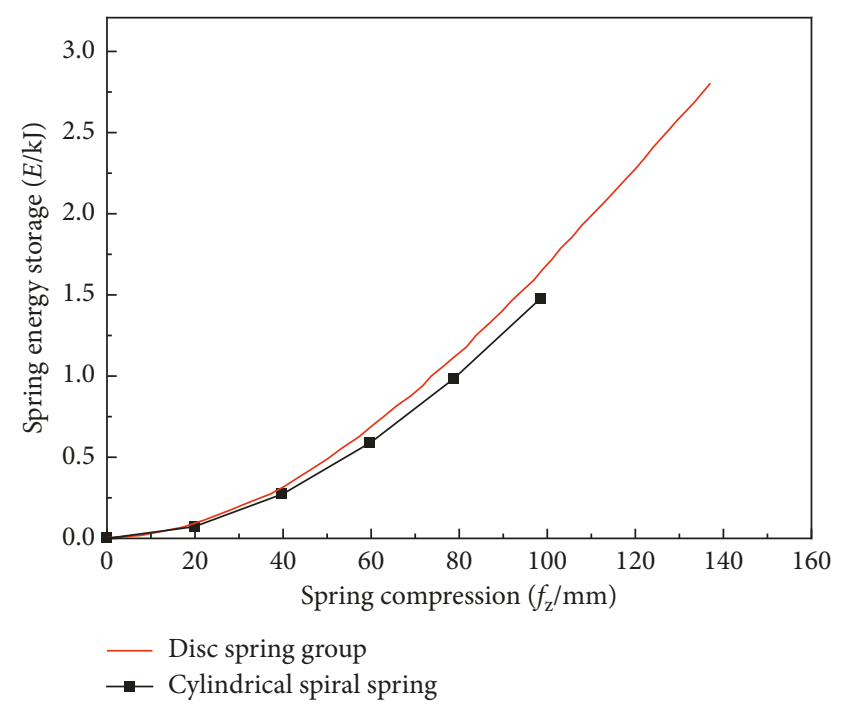

Figure 14: Energy storage values of two types of springs.

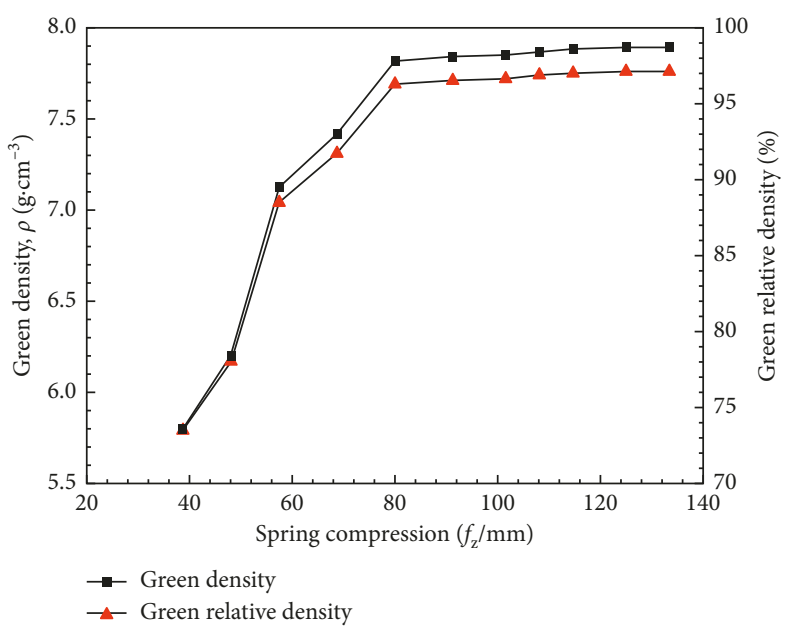

Figure 15: Spring compression versus green density.

the green density increases from $6.17 \mathrm{~g} / \mathrm{cm}^{3}$ to $7.04 \mathrm{~g} / \mathrm{cm}^{3}$ rapidly, with an overall increase of $14.1 \%$; and when it increases from $90 \mathrm{~mm}$ to $120 \mathrm{~mm}$, the green density increases from $7.71 \mathrm{~g} / \mathrm{cm}^{3}$ to $7.75 \mathrm{~g} / \mathrm{cm}^{3}$, with an overall increase of $0.5 \%$. This phenomenon is consistent with the HVC mechanism. When the spring compression reaches $140 \mathrm{~mm}$, the compact density is approximately $7.76 \mathrm{~g} / \mathrm{cm}^{3}$ and the relative density is $98.7 \%$. The density is higher than the value of $7.70 \mathrm{~g} / \mathrm{cm}^{3}$ of the compact made by combining powder annealing with the HVC method.

\section{Conclusions}

(1) The impact energy storage of the HVC machine was developed by using the combination disc springs to modify the existing machine. The design indicator of $3000 \mathrm{~J}$ was reached in the developed industrial prototype machine.

(2) The hydraulic control method was presented to automatically control the impact energy of the 
machine via controlling the spring's compression. The communication between the PLC controller and the touch screen was implemented by the developed program.

(3) A human-computer interactive control simulation platform was created. By using the interface of LabVIEW and AMESim, a controllable mechanicalhydraulic cosimulation platform was established, and then, an ADAMS virtual prototype of the test machine was controlled by LabVIEW.

(4) Using the experimental research of the iron powder HVC, the presented mathematical model of energy storage was verified. Furthermore, the corresponding relations among spring compression, spring energy, and green density were analyzed, and the relative density of the green compact was found to be improved.

\section{Data Availability}

The datasets used to support this study cannot be made freely available at this time as the data also form part of an ongoing study. Access to these data will be considered by the corresponding author upon request.

\section{Conflicts of Interest}

The authors declare that they have no conflicts of interest.

\section{Acknowledgments}

This work was supported by the Natural Science Foundation of Guangdong Province (Grant nos. 2017A030313320 and 2015A030312003), the Guangdong Application-Oriented Special Funds for Science and Technology R\&D (Grant no. 2016B090931002), the National Natural Science Foundation of China (Grant no. 51574128), the Fundamental Research Funds for the Central Universities (Grant no. 2017PY014), and the Open Fund of Metastable Materials Science and Technology State Key Laboratory of Yanshan University (Grant no. 201712).

\section{References}

[1] L. Z. Zhao, X. X. Deng, H. Y. Yu et al., "Structure and performance of anisotropic nanocrystalline Nd-Fe-B magnets fabricated by high-velocity compaction followed by deformation," Journal of Magnetism and Magnetic Materials, vol. 443, pp. 51-57, 2017.

[2] H. Z. Zhang, L. Zhang, G. Q. Dong et al., "Effects of annealing on high velocity compaction behavior and mechanical properties of iron-base PM alloy," Powder Technology, vol. 288, pp. 435-440, 2016.

[3] A. Vivek, J. D. DeFouw, and G. S. Daehn, "Dynamic compaction of titanium powder by vaporizing foil actuator assisted shearing," Powder Technology, vol. 254, pp. 181-186, 2014.

[4] H. Babaei, T. M. Mostofi, and M. Namdari-Khalilabad, "Gas mixture detonation method, a novel processing technique for metal powder compaction: experimental investigation and empirical modeling," Powder Technology, vol. 315, pp. 171181, 2017.

[5] G. Sethi, N. S. Myers, and R. M. German, "An overview of dynamic compaction in powder metallurgy," International Materials Reviews, vol. 53, no. 4, pp. 219-234, 2008.

[6] P. Doremus, Y. L. Guennec, D. Imbault, and G. Puente, "High-velocity compaction and conventional compaction of metallic powders; comparison of process parameters and green compact properties," Proceedings of The Institution of Mechanical Engineers Part E-Journal of Process Mechanical Engineering, vol. 224, no. 3, pp. 177-185, 2010.

[7] Z. Q. Yan, F. Chen, F. X. Ye, D. P. Zhang, and Y. X. Cai, "Microstructures and properties of $\mathrm{Al}_{2} \mathrm{O}_{3}$ dispersionstrengthened copper alloys prepared through different methods," International Journal of Minerals, Metallurgy, and Materials, vol. 23, no. 12, pp. 1437-1443, 2016.

[8] H. Zhang, L. Zhang, G. Dong, Z. Liu, M. Qin, and X. H. Qu, "Effects of warm die on high velocity compaction behaviour and mechanical properties of iron based PM alloy," Powder Metallurgy, vol. 59, no. 2, pp. 100-106, 2016.

[9] H. Y. Park, M. F. Kilicaslan, and S. J. Hong, "Effect of multiple pressures by magnetic pulsed compaction (MPC) on the density of gas-atomized Al-20Si powder," Powder Technology, vol. 224, pp. 360-364, 2012.

[10] G. S. Jiang, Z F. Wang, Y. Gu, Q. W. Zhang, Y. Gao, and $\mathrm{K}$. Kuang, "Fabrication of electronic packaging grade $\mathrm{Cu}-\mathrm{W}$ materials by high-temperature and high-velocity compaction," IEEE Transactions on Components, Packaging and Manufacturing Technology, vol. 2, no. 6, pp. 1039-1042, 2012.

[11] M. Shoaib and L. Kari, "Non-linear elasto-plastic shock wave simulation in high-velocity compaction by discrete element method," in Proceedings of the 19th International Symposiumon Nonlinear Acoustics, Waseda University, Acoustical Society of Japan; Acoustical Society of America; International Union of Pure and Applied Physics; Nonlinear Acoustics Society Japan: State-of-The-Art And Perspectives, AIP Conference Proceedings, vol. 1474, pp. 172-175, Tokyo, Japan, May 2012.

[12] Q. J. Li, Z. S. Zheng, and X. H. Qu, "Simulation of high velocity compaction of powder in a two dimension mould using lattice Boltzmann method," Acta Metallurgica Sinica, vol. 25, no. 1, pp. 47-54, 2012.

[13] S. Wang, Z. S. Zheng, and W. Zhou, "The pressure wave analysis in high velocity compaction process," Acta Physica Sinica, vol. 60, no. 12, article 128101, 2011.

[14] Z. Q. Yan, F. Chen, Y. X. Cai, and L. Cui, "High velocity compaction and characteristics of Ti powder," Acta Metallurgica Sinica, vol. 46, no. 2, pp. 227-232, 2010.

[15] X. J. Yuan, H. Q. Yin, R. U. Din, D. F. Khan, and X. H. Qu, "Study on the impact force and green properties of highvelocity compacted aluminum alloy powder," International Journal of Minerals, Metallurgy, and Materials, vol. 19, no. 12, pp. 1107-1113, 2012.

[16] D. F. Khan, H. Q. Yin, H. Li et al., "Compaction of Ti-6Al-4V powder using high velocity compaction technique," Materials \& Design, vol. 50, pp. 479-483, 2013.

[17] D. F. Khan, H. Q. Yin, H. Li et al., "Effect of impact force on Ti-10Mo alloy powder compaction by high velocity compaction technique," Materials \& Design, vol. 54, pp. 149-153, 2014.

[18] J. Z. Wang, H. Q. Yin, and X. H. Qu, “Analysis of density and mechanical properties of high velocity compacted iron powder," Acta Metallurgica Sinica, vol. 22, no. 6, pp. 447-453, 2009. 
[19] H. Li, H. Q. Yin, D. F. Khan, H. Q. Cao, Z. Abideen, and X. H. Qu, "High velocity compaction of $0.9 \mathrm{Al} 2 \mathrm{O} 3 / \mathrm{Cu}$ composite powder," Materials \& Design, vol. 57, pp. 546-550, 2014.

[20] X. X. Deng, Z. W. Liu, H. Y. Yu, Z. Y. Xiao, and G. Q. Zhang, "Isotropic and anisotropic nanocrystalline $\mathrm{NdFeB}$ bulk magnets prepared by binder-free high-velocity compaction technique," Journal of Magnetism and Magnetic Materials, vol. 390, pp. 26-30, 2015.

[21] X. X. Deng, L. Z. Zhao, H. Y. Yu, Z. W. Liu, and Z. Y. Xiao, "Preparation of isotropic and anisotropic nanocrystalline $\mathrm{NdFeB}$ magnets by high-velocity compaction and hot deformation," IEEE Transactions on Magnetics, vol. 51, no. 11, article 2104804, 2015.

[22] Z. Q. Yan, F. Chen, and Y. X. Cai, "High velocity compaction behavior and sintered properties of Ti powders with different particle sizes," Acta Metallurgica Sinica, vol. 48, no. 3, pp. 379-384, 2012.

[23] Z. Q. Yan, F. Chen, Y. X. Cai, and J. Yin, "Influence of particle size on property of Ti-6Al-4V alloy prepared by high-velocity compaction," Transactions of Nonferrous Metals Society of China, vol. 23, no. 2, pp. 361-365, 2013.

[24] Z. Q. Yan, F. Chen, Y. X. Cai, J. Yin, and Y. K. Zheng, "Preparation and properties of Ti-4.5Al-6.8Mo-1.5Fe alloy by high-velocity compaction," Powder Technology, vol. 246, pp. 345-350, 2013.

[25] M. Eriksson, H. Å. Häggblad, C. Berggren, M. Andersson, R. Holmersson, and E. Carlström, "New semi-isostatic high velocity compaction method to prepare titanium dental copings," Powder Metallurgy, vol. 47, no. 4, pp. 335-342, 2004.

[26] G. Gustafsson, M. Nishida, H. Å. Häggblad, H. Katob, P. Jonsén, and T. Ogura, "Experimental studies and modelling of high-velocity loaded iron-powder compacts," Powder Technology, vol. 268, pp. 293-305, 2014.

[27] M. Shoaib, L. Kari, and B. Azhdar, "Simulation of highvelocity compaction process with relaxation assists using the discrete element method," Powder Technology, vol. 217, pp. 394-400, 2012.

[28] D. F. Khan, H. Q. Yin, Z. Usman et al., "Improvement of a high velocity compaction technique for iron powder," Acta Metallurgica Sinica, vol. 26, no. 4, pp. 399-403, 2013.

[29] B. Bos, C. Fors, and T. Larsson, "Industrial implementation of high velocity compaction for improved properties," Powder Metallurgy, vol. 49, no. 2, pp. 107-109, 2006.

[30] C. Y. Ma, Z. Y. Xiao, C. Li, and J. Chen, "Recent progress on high velocity compaction technology in powder metallurgy," Powder Metallurgy India, vol. 22, no. 2, pp. 56-60, 2012.

[31] H. J. Guan, M. Shao, and Z. Y. Xiao, "Study on mechanical energy stored type powder high velocity compaction machine," Journal of South China University of Technology: Natural Sciences Education, vol. 40, no. 12, pp. 53-57, 2012.

[32] X. W. Zhao, Q. C. Zhao, W. Z. Li, and H. B. Yang, "Secondorder consensus predictive control for 360MN extrusion machine," Control Engineering Practice, vol. 39, pp. 103-112, 2015.

[33] Y. Ye, C. B. Yin, and Y. Gong, "Position control of nonlinear hydraulic system using an improved PSO based PID controller," Mechanical Systems and Signal Processing, vol. 83, pp. 241-259, 2017.

[34] L. P. Zhang, D. C. Cong, and Z. D. Yang, "Robust tracking and synchronization of double shaking tables based on adaptive sliding mode control with novel reaching law," IEEE Access, vol. 4, pp. 8686-8702, 2016.
[35] Q. L. Zeng, K. D. Gao, H. Z. Zhang, S. B. Jiang, and K. Jiang, "Vibration analysis of shearer cutting system using mechanical hydraulic collaboration simulation," Proceedings of the Institution of Mechanical Engineers, Part K: Journal of Multi-body Dynamics, vol. 231, no. 4, pp. 708-725, 2017.

[36] Y. Dai, X. Zhu, and LS. Chen, "A mechanical-hydraulic virtual prototype co-simulation model for A seabed remotely operated vehicle," International Journal of Simulation Modelling, vol. 15, no. 3, pp. 532-541, 2016.

[37] X. W. Rong, Y. B. Li, J. H. Ruan, and B. Li, "Design and simulation for a hydraulic actuated quadruped robot," Journal of Mechanical Science and Technology, vol. 26, no. 4, pp. 1171-1177, 2012.

[38] Y. G. Sun, W. L. Li, D. H. Dong, X. Mei, and H. Y. Qiang, "Dynamics analysis and active control of a floating crane," Tehnicki Vjesnik-Technical Gazette, vol. 22, no. 6, pp. 13831391, 2015.

[39] T. L. Lin, L. Wang, W. P. Huang, H. L. Ren, S. J. Fu, and Q. H. Chen, "Performance analysis of an automatic idle speed control system with a hydraulic accumulator for pure electric construction machinery," Automation in Construction, vol. 84, pp. 184-194, 2017.

[40] S. J. Guo, Y. Chi, F. Meng, and X. Yang, "Compaction equation for high velocity compact shaping of powder metallurgy," Materials Science and Engineering Powder Metallurgy, vol. 11, no. 1, pp. 24-27, 2006.

[41] Y. H. Zhang, H. H. Liu, and D. C. Wang, Spring Manual, Mechanical Industry Press 5, Beijing, China, 2017.

[42] L. H. Xu, X. W. Fan, and Z. X. Li, "Cyclic behavior and failure mechanism of self-centering energy dissipation braces with pre-pressed combination disc springs," Earthquake Engineering \& Structural Dynamics, vol. 46, no. 7, pp. 1065-1080, 2017. 


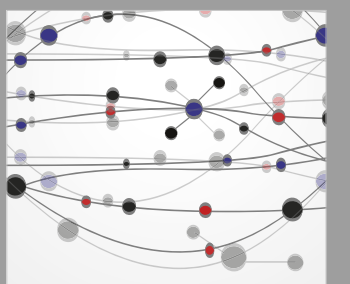

The Scientific World Journal
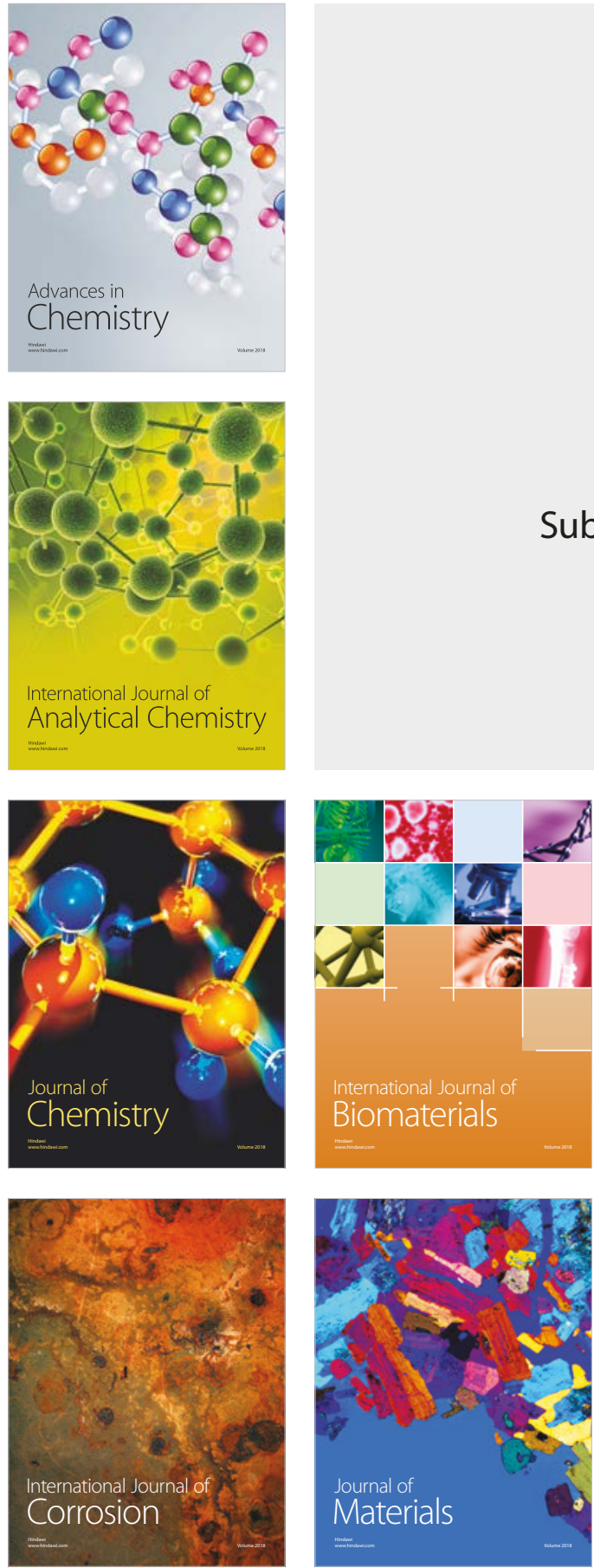

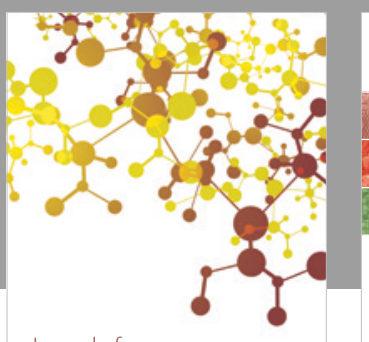

Journal of

Applied Chemistry
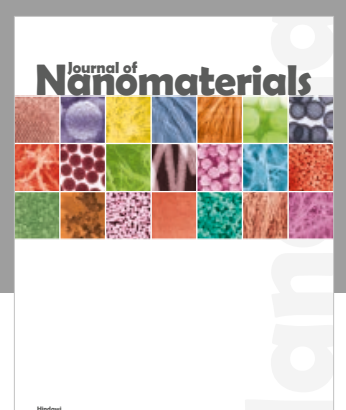

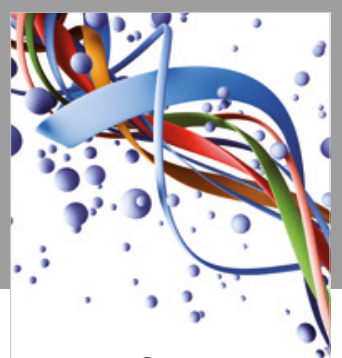

Scientifica

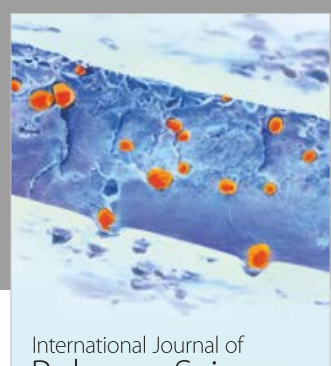

Polymer Science

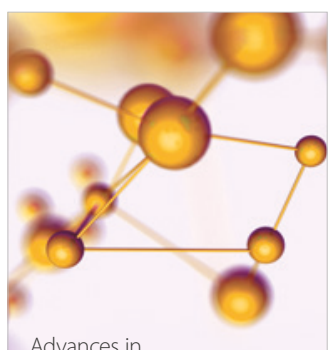

Physical Chemistry
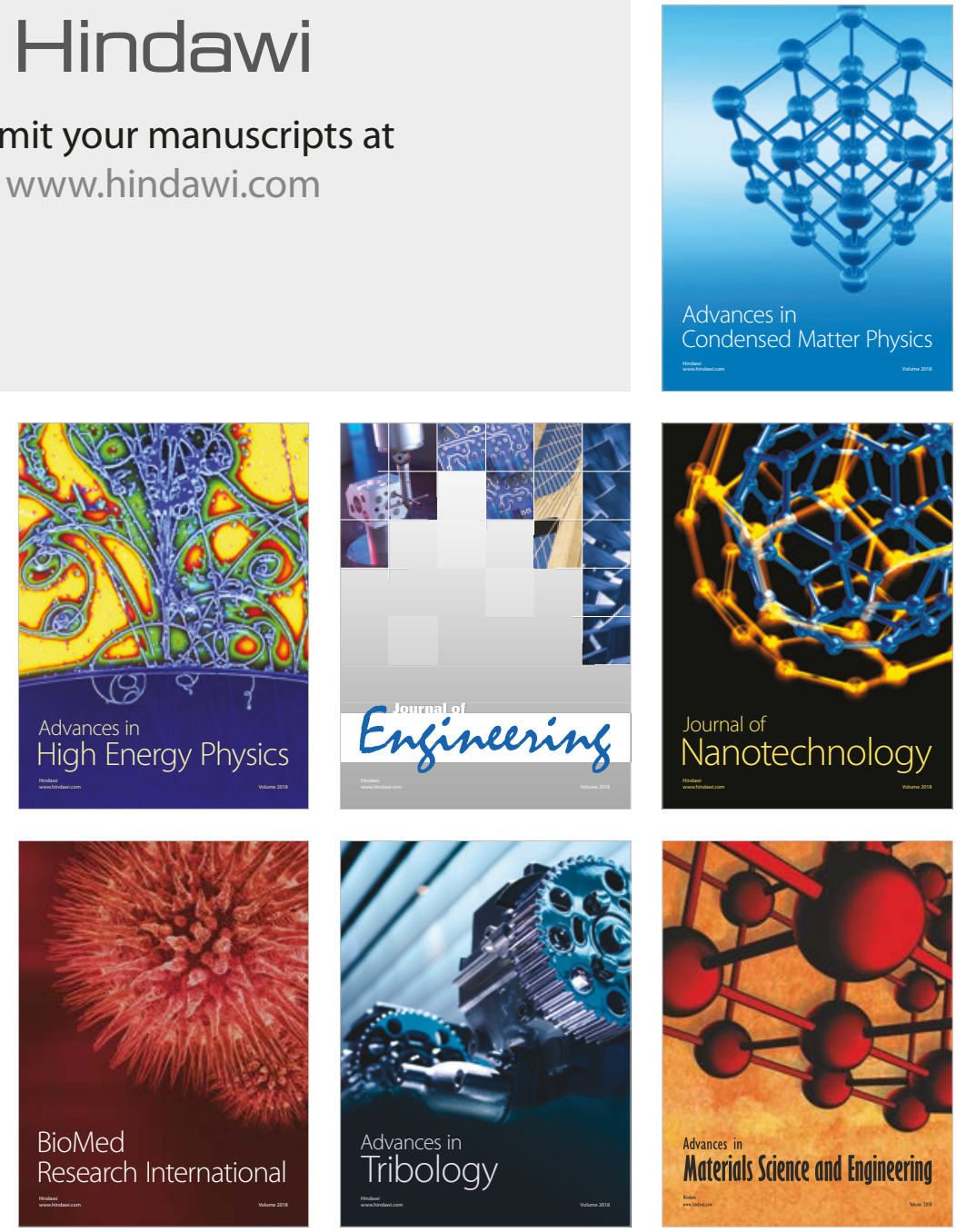